\title{
Different Effects of Castration and Estrogen Administration on Glomerular Injury in Spontaneously Hyperglycemic Otsuka Long-Evans Tokushima Fatty (OLETF) Rats
}

\author{
Yoshiyuki Tomiyoshi Takanobu Sakemi Shigehisa Aoki Motoaki Miyazono \\ From the Department of Internal Medicine, Saga Medical School, Saga, J apan
}

\section{Key Words}

Castration · Estrogen · Glomerulosclerosis · Diabetes mellitus · Rat

\begin{abstract}
Aim: Non-insulin-dependent diabetic mellitus model rats, Otsuka-Long-Evans-Tokushima-Fatty (OLETF), develop diabetic nephropathy presenting with mesangial expansion leading to glomerular sclerosis and thickening of the glomerular basement membrane (GBM), especially in elderly males. The effects of sex hormones and castration on the incidence of diabetes mellitus (DM) have been studied in this strain rat. However, there have been no detailed studies on the effects of castration and sex hormone in the development of diabetic nephropathy. Methods: In this study we examine the effect of castration or estrogen on the development of glomerular injury in OLETF rats. Thirty male OLETF rats and 10 male long-Evans Tokushima Otsuka (LETO) rats as a normal control were used. OLETF rats were divided into three groups: group 1 received sham-operation, group 2 was castrated at 6 weeks, and group 3 was administered $0.1 \mathrm{mg}$ estrogen subcutaneously once a month from 6 weeks to 58 weeks of age and LETO rats were assigned
\end{abstract}

to group 4. Body weight, urinary protein and fasting blood glucose, serum albumin and other serum constituents were investigated every 12 weeks from 12 weeks to 60 weeks of age. In groups 1-3, glucose tolerance test was performed at 38 weeks. Each group was studied morphologically at the end of the experiment ( 60 weeks of age). Results: Castration attenuated proteinuria and glomerular sclerosis accompanied by an amelioration of glucose tolerance, a decrease in mesangial expansion and an attenuation of the GBM thickening. In contrast, although estrogen equally ameliorated glucose tolerance and attenuated the mesangial expansion and the GBM thickening, estrogen failed to attenuate proteinuria and glomerulosclerosis. A significant increase in glomerular tuft volume, and serum levels of growth hormone, total cholesterol and triglycerides was observed in the estrogen-treated rats as compared with the castrated rats. Conclusion: Besides the mechanisms involved in the development of diabetic nephropathy, other mechanisms may be involved and contribute to the development of glomerulosclerosis in the estrogen-treated rats, leading to a difference in glomerular injury between the castrated and estrogen-treated OLETF rats.

Copyright $\odot$ 2002 S. Karger AG, Basel

\begin{tabular}{ll}
\hline KARGER & @ 2002 S. Karger AG, Basel \\
Fax +4161 306 12 34 & 0028-2766/02/0924-0860\$18.50/0 \\
$\begin{array}{l}\text { E-Mail karger@karger.ch } \\
\text { www.karger.com }\end{array}$ & $\begin{array}{l}\text { Accessible online at: } \\
\text { www.karger.com/journals/nef }\end{array}$
\end{tabular}

Yoshiyuki Tomiyoshi, MD
Department of Internal Medicine, Saga Medical School
Nabeshima, Saga 849-8501 (Japan)
Tel. +81 952 34 2372, Fax +81 952 342017
E-Mail tomiyoshi-yoshiyuki@kouseikan.saga.saga.jp 


\section{Introduction}

A spontaneously diabetic rat with polyuria, polydipsia, and slight obesity was discovered in an outbred colony of Long-Evans (LE) rats, which had been purchased from Charles Rive Canada (St. Constant, Quebec) in 1982 and subsequently maintained at the Tokushima Research Institute, Otsuka Pharmaceutical (Tokushima, Japan). A diabetic strain was established by selective breeding in 1990 and has been named the Otsuka-Long-Evans-Tokushima-Fatty (OLETF) strain [1]. From the same LE stock, a control line, Long-Evans Tokushima Otsuka (LETO) has also been established [1]. This non-insulin-dependent diabetes mellitus model OLETF rats show a sex difference in the incidence of diabetes mellitus. Almost 100\% of male OLETF rats develop diabetes at 25 weeks of age, whereas only $30 \%$ of the female are affected after 60 weeks.

The sex difference and the role of sex hormones in the development of diabetes have been investigated [2-4]. However, there have been no detailed studies on the effects of castration and sex hormone in the development of diabetic nephropathy because of a lack of typical models of a spontaneous diabetic nephropathy rat, although the effects of sex hormones and castration on the incidence of diabetes mellitus (DM) have been studied in this strain rat $[5,6]$. Because the diabetic glomerular lesions have been reported to occur in elderly OLETF rats [7], in this study we examine the effect of castration or estrogen on the development of glomerular injury in elderly OLETF rats.

\section{Materials and Methods}

\section{Experimental Design}

Thirty male OLETF rats and 10 male LETO rats were obtained from Tokushima Research Institute, Otsuka Pharmaceutical. They were fed standard rat chow (Clea Japan Inc., Tokyo, Japan) containing $0.39 \% \mathrm{NaCl}$ and $24.8 \%$ protein, and OLETF rats were divided into three groups of 10 rats. At 6 weeks of age, group 1 (control OLETF) received sham-operation and group 2 (Cast) received castration. Group 3 (Est) received estrogen treatment and LETO rats were assigned to group 4 (LETO). Estradiol valerate, purchased from Japan Schering Co., was diluted in sesame oil to a concentration of $1 \mathrm{mg} / \mathrm{ml}$ and the vehicle or the selected dose with $0.1 \mathrm{ml}$ of volume was given subcutaneously once a month from 6 to 58 weeks of age according to the method reported before [8]. The estrogen dose was determined based on our previous study [8].

Blood pressure (BP), body weight $(\mathrm{BW})$, urinary protein, fasting blood glucose, serum albumin (Alb), total cholesterol (Tchol), blood urea nitrogen (BUN) and serum creatinine $(\mathrm{Cr})$ were investigated every 12 from 12 weeks to 60 weeks of age. Systolic BP was measured in conscious rats by the tail cuff method, with warming for $10 \mathrm{~min}$ at $37^{\circ} \mathrm{C}$ before measurement. At 60 weeks of age, 10 rats of each group were exsanguinated from the aorta and trunk blood was collected. The study was performed in accordance with the guidelines of the Animal Experimental Guide of Saga Medical School.

Twenty-four-hour urinary protein was measured by the pyrogallol red method [9]. Fasting blood samples were obtained via percutaneous puncture of the tail vein. Serum protein was measured by the Biuret method [10] and the protein fraction was analyzed electrophoretically. BUN was measured by the urease indophenol method and serum creatinine by using Jaffe's method [11]. Serum cholesterol was determined by an enzymatic method [12]. Blood glucose was measured by the glucose dehydrogenase method [13]. Serum testosterone and growth hormone $(\mathrm{GH})$ were determined by employing a radioimmunoassay [14].

At 38 weeks of age, glucose tolerance tests were performed. The rats were fasted overnight followed by intraperitoneal glucose injection $(2 \mathrm{~g} / \mathrm{kg}$ body weight). Whole venous blood was obtained from the tail vein at $0,30,60,90$ and $120 \mathrm{~min}$ after the injection.

\section{Renal Histological Examination}

Animals were sacrificed at 60 weeks of age. The abdominal aorta was catheterized retrogradely. Firstly, the right kidney for electron microscopy was removed after clamping the right renal artery and vein. Subsequently, the left kidney for morphometric analysis was flushed with saline and perfused directly for $3 \mathrm{~min}$ at a pressure of $100 \mathrm{~mm} \mathrm{Hg}$ with $10 \%$ neural buffered formalin and removed. Coronal slices were embedded in paraffin for light-microscopic study. Sections of $2 \mu \mathrm{m}$ in thickness were stained with hematoxylin and eosin, periodic acid-Schiff reagent (PAS) and periodic acid-methenamine silver. Histological evaluation was done by a pathologist (S.A.) blind to the origin of the samples. The degree of glomerular sclerosis was evaluated semiquantitatively after Raij et al. [15]. At least 100 glomeruli were examined. The severity of the lesions was graded from 0 to $4+$ according to the percentage of glomerular sclerosis, where $1+=$ $25 \%$, while $4+=100 \%$. An injury score was then obtained by multiplying the severity of damage ( 0 to $4+$ ) by the percentage of glomeruli with the same degree of injury. The extent of injury for each individual tissue specimen was then obtained by adding the scores. Tubulointerstitial change including tubular dilatation, atrophy, proteinaceous casts, interstitial edema and mononuclear cell infiltrates was graded from 0 to $4+$ according to the method described previously [16].

Mesangial expansion was determined by the automatic image analyzer, using the modification of the method described previously [17]. Ten glomeruli with cross-section through their vascular poles was randomly chosen from 5 rats of each group. We measured the total glomerular area and the PAS-positive staining glomerular area and then calculated the percentages of PAS-positive areas with respect to the total glomerular areas (fractional mesangial volume).

Glomerular tuft volume (GV) was determined as described by Weibel [18] with a slight modification. Histological sections were projected on a video image (enlargement $\times 200$ ), using a light microscope and a drawing tube. Outlines of the capillary tufts on the video image were traced manually with an overlay board; these areas were measured using an image analysis system (Videoplan, Kontron Bildanalyse, Munich, Germany). Mean glomerular random cross-section areas $(\mathrm{Am})$ were determined in at least 50 glomeruli encountered on a serpentine course between the cortex and the medulla in each animal. Thus no glomerulus was counted more than once and all levels of 
Fig. 1. Changes in body weight in control $(O)$, castrated $(\bullet)$, estrogen-treated $(\square)$ OLETF rats and LETO rats $(\boldsymbol{\square}) .{ }^{\mathrm{a}} \mathrm{p}<0.05$, ${ }^{\mathrm{b}} \mathrm{p}<0.01,{ }^{\mathrm{c}} \mathrm{p}<0.001$ vs. control OLETF.

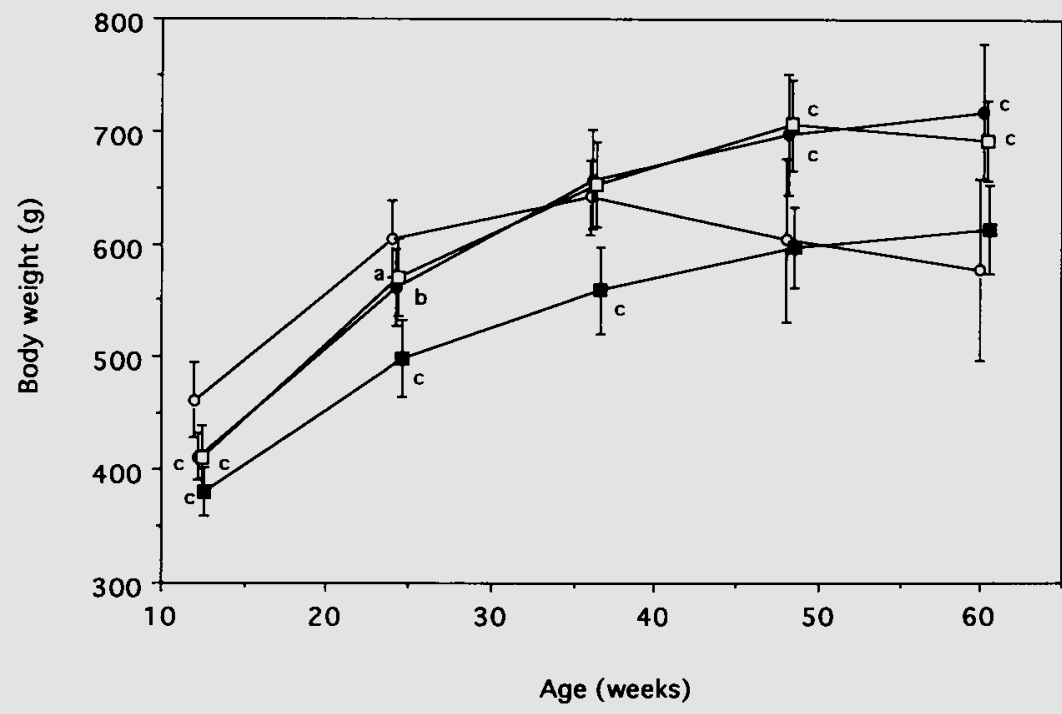

cortex were evenly sampled. Mean volume of capillary tufts was calculated using the equation derived by Weibel [18]:

$$
\mathrm{V}=(\beta / \alpha)(\mathrm{Am})^{3 / 2},
$$

where $\alpha=1.1$ is the size distribution coefficient and $\beta=1.38$ is the shape coefficient for spheres (the assumed shape of glomeruli).

Tissues for electron microscopy were fixed with 3\% glutaraldehyde, washed in cacodylate buffer, postfixed in osmium tetroxide, dehydrated in graded alcohols and embedded in Epon 812. Ultrathin sections were double-stained with uranyl acetate and lead citrate and observed with an electron microscope. Glomerular basement membrane (GBM) thickness was measured in 5 rats of each group by the orthogonal intercept method described by Jensen et al. [19]. In brief, a grid with eight evenly spaced intersecting lines (four horizontal and four vertical) was placed over each photomicrograph and the GBM measurement was made at each point that a line on the grid intercepts an endothelial-GBM interface. The width was measured on a line orthogonal to the edge of the GBM at the endothelial side of the intercept. A mean of 100 measurements was obtained on 2-3 glomeruli. Actual GBM thickness was obtained by the harmonic mean multiplied by $8 / 3 \mathrm{p}$ [19].

\section{Statistical Analysis}

Data were analyzed using StatView J-4.5, a commercial statistics program (Abacus Concepts, Inc. Berkeley, Calif., USA). Data were first analyzed for distribution. Results were expressed as arithmetic mean values $\pm \mathrm{SD}$. The other data were tested by one-way or twoway analysis of variance (ANOVA) and the method of Bonferroni/ Dunn for multiple comparisons was applied if the variance ratio $(\mathrm{F})$ reached statistical significance $(\mathrm{p}<0.05)$.

\section{Results}

\section{Body Weight}

The effect of castration or estrogen on growth rate is shown in figure 1. BW in the control OLETF rats was increased until 36 weeks of age, but thereafter growth rate was stunted and reduced. BW in Cast rats or Est rats was also significantly increased, though lower than that of controls before 36 weeks, but thereafter growth rate was not stunted and significantly increased as compared with that of controls until 60 weeks of age. LETO rats grew with age without any reduction of $\mathrm{BW}$, though growth rate was stunted significantly as compared with that of Cast or Est rats throughout the experimental period.

\section{Blood Pressure}

The systolic blood pressure was measured at five points during the experiment and the mean BPs of five points of control OLETF rats, Cast rats, Est rats and LETO rats were as follows: $163 \pm 12,158 \pm 13,173 \pm 19$ and $148 \pm 18 \mathrm{~mm} \mathrm{Hg}$, respectively. There were significant differences in BP among the four groups, when compared using two-way ANOVA with repeated measure. BPs in LETO rats were significantly lower than those of other three groups ( $\mathrm{p}<0.05$ for each) and BPs in Cast rats were significantly lower than those of Est rats $(p<0.05)$. There were no significant differences between control OLETF rats and Cast rats or Est rats. 
Fig. 2. Changes in urinary protein excretion rates in control $(O)$, castrated $(\bullet)$, estrogentreated $(\square)$ OLETF rats and LETO rats ( $\square$ ). When compared with two-way ANOVA, significant differences are observed between control OLETF rats and castrated OLETF rats or LETO rats $(\mathrm{p}<0.001$ for each).

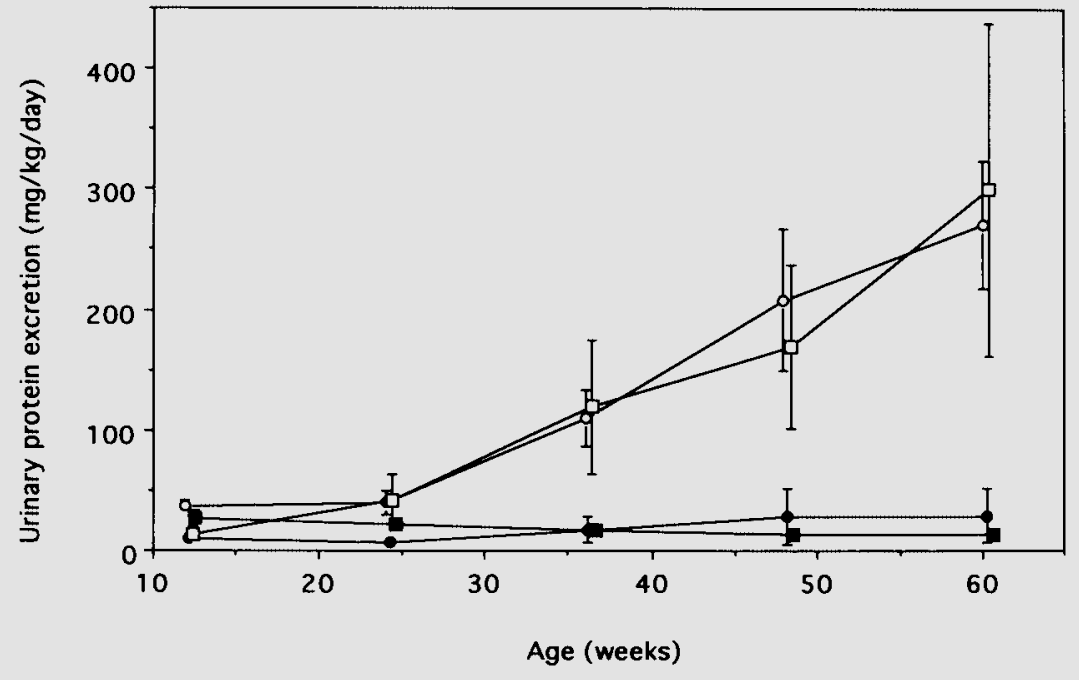

Age (weeks)

\section{Proteinuria}

Urinary protein excretion rates are shown in figure 2.

Control OLETF rats became more proteinuric than LETO rats from 36 weeks of age and its excretion rates reached a mean value of $271 \pm 53 \mathrm{mg} / \mathrm{kg} /$ day at 60 weeks of age. Castration significantly reduced the urinary protein excretion rates to levels of LETO rats (Cast rats $29 \pm$ $23 \mathrm{mg} / \mathrm{kg} / \mathrm{day}$, LETO rats $14 \pm 2 \mathrm{mg} / \mathrm{kg} / \mathrm{day}$ at 60 weeks), while estrogen treatment did not influence its rates which were almost equal to those of control OLETF rats throughout the experimental period (Est rats $300 \pm 139$ $\mathrm{mg} / \mathrm{kg} /$ day at 60 weeks).

\section{Blood Glucose and Glucose Tolerance Test}

Fasting blood glucose levels were measured at five points during the experiment and the mean blood glucose levels of five points of control OLETF rats, Cast rats, Est rats and LETO rats were as follows: $186 \pm 29,199 \pm 25$, $194 \pm 52$ and $137 \pm 27 \mathrm{mg} / \mathrm{dl}$, respectively. There were significant differences in blood glucose levels among the four groups, when compared using two-way ANOVA with repeated measure. Blood glucose levels were higher in control OLETF rats, Cast rats and Est rats than LETO rats ( $p<0.001$ for each), but no differences were observed among the three OLETF groups. As shown in figure 3, castration and estrogen administration equally ameliorated glucose tolerance $(\mathrm{p}<0.03$, control OLETF rats vs. Cast rats or Est rats).

Effect of Castration and Estrogen in OLETF Rats

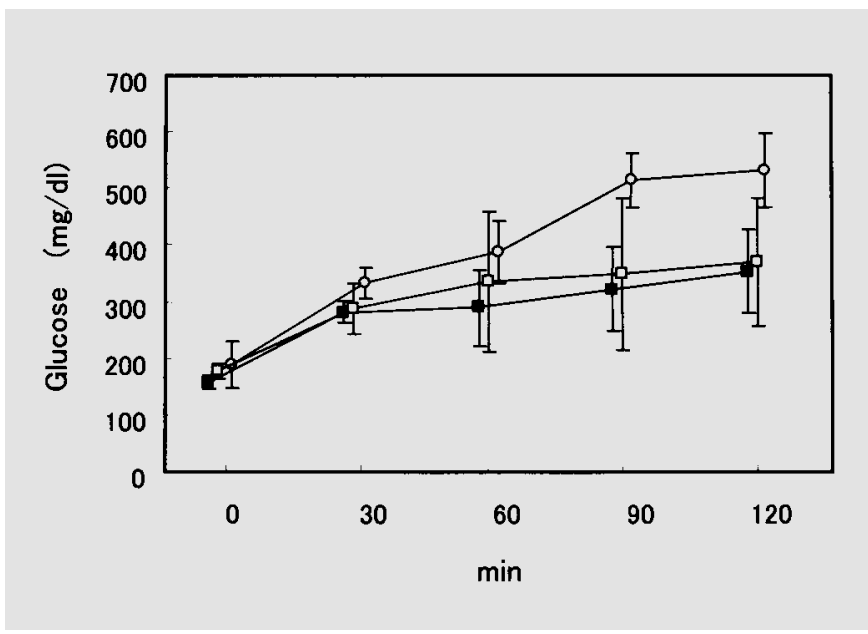

Fig. 3. Glucose tolerance test at 38 weeks of age in control $(\bigcirc)$, castrated ( $\square$ ) and estrogen-treated ( $\square$ ) OLETF rats. When compared with repeated measure ANOVA, significant differences are observed between the control OLETF rats and the castrated or estrogentreated OLETF rats $(\mathrm{p}<0.05$ for each).

\section{Organ Weight and Serum Constituents}

As shown in table 1, castration reduced significantly kidney weight $(\mathrm{KW})$ to levels of the LETO rats and tended to reduce heart weight (HW). Estrogen treatment slightly reduced $\mathrm{KW}$, but did not influence HW. Castration resulted in higher albumin levels and a lesser impairment

Nephron 2002;92:860-867 863 
Table 1. Serum constituents at the end of the experiment (60 weeks of age)

\begin{tabular}{llllllllll}
\hline Group & $\mathrm{n}$ & $\begin{array}{l}\mathrm{KW} \\
\mathrm{g}\end{array}$ & $\begin{array}{l}\mathrm{HW} \\
\mathrm{g}\end{array}$ & $\begin{array}{l}\text { Albumin } \\
\mathrm{g} / \mathrm{dl}\end{array}$ & $\begin{array}{l}\mathrm{T} \text { chol } \\
\mathrm{mg} / \mathrm{dl}\end{array}$ & $\begin{array}{l}\mathrm{TG} \\
\mathrm{mg} / \mathrm{dl}\end{array}$ & $\begin{array}{l}\mathrm{BUN} \\
\mathrm{mg} / \mathrm{dl}\end{array}$ & $\begin{array}{l}\mathrm{GH} \\
\mathrm{ng} / \mathrm{ml}\end{array}$ & $\begin{array}{l}\text { Testosterone } \\
\mathrm{ng} / \mathrm{dl}\end{array}$ \\
\hline G1: control & 10 & $2.20 \pm 0.18$ & $2.16 \pm 0.40$ & $3.7 \pm 0.4$ & $133 \pm 23$ & $199 \pm 42$ & $22.0 \pm 7.0$ & $16.9 \pm 2.3$ & $19.9 \pm 11.1$ \\
Gs: Cast & 10 & $1.31 \pm 0.26$ & $1.86 \pm 0.27$ & $4.3 \pm 0.5$ & $106 \pm 29$ & $158 \pm 66$ & $13.9 \pm 2.3$ & $21.0 \pm 6.8$ & $<5$ \\
G3: strogen & 10 & $1.90 \pm 0.27$ & $2.31 \pm 0.30$ & $3.9 \pm 0.4$ & $215 \pm 39$ & $280 \pm 81$ & $19.0 \pm 6.1$ & $46.4 \pm 10.8$ & $9.5 \pm 4.5$ \\
Ge: LETO & 10 & $1.36 \pm 0.10$ & $2.09 \pm 0.50$ & $4.3 \pm 0.2$ & $103 \pm 5$ & n.d. & $15.9 \pm 2.5$ & n.d. & n.d. \\
\hline p G1 vs. G2 & $<0.001$ & $\mathrm{NS}$ & $<0.01$ & $\mathrm{NS}$ & $\mathrm{NS}$ & $<0.01$ & $\mathrm{NS}$ & $<0.005$ \\
G1 vs. G3 & $<0.01$ & $\mathrm{NS}$ & $\mathrm{NS}$ & $<0.001$ & $<0.001$ & $\mathrm{NS}$ & $<0.001$ & $<0.01$ \\
G1 vs. G4 & $<0.001$ & $\mathrm{NS}$ & $<0.01$ & $\mathrm{NS}$ & & $<0.05$ & $<0.001$ & $<0.01$ \\
G2 vs. G3 & $<0.001$ & $<0.05$ & $\mathrm{NS}$ & $<0.001$ & $<0.001$ & $\mathrm{NS}$ & $<$ & \\
G2 vs. G4 & $\mathrm{NS}$ & $\mathrm{NS}$ & $\mathrm{NS}$ & $\mathrm{NS}$ & & $\mathrm{NS}$ & & \\
G3 vs. G4 & $<0.001$ & $\mathrm{NS}$ & $\mathrm{NS}$ & $<0.001$ & & $\mathrm{NS}$ & & \\
\hline
\end{tabular}

$\mathrm{TG}=$ Triglycerides; NS = not significant; n.d. = not done.

of renal function with regard to BUN levels as compared with those of control OLETF rats, though no significant difference in serum creatinine levels was observed among the four groups (data not shown). In contrast, estrogen administration did not exert any beneficial effects on either albumin or BUN levels which were almost equal to those of control OLETF rats and significantly increased serum Tchol and triglycerides levels. Castration or estrogen treatment significantly reduced serum testosterone levels, to a greater extent in Cast rats than in Est rats. Castration did not influence serum GH levels, while estrogen treatment significantly increased those levels.

\section{Pathology}

Histological abnormalities included focal and segmental glomerular hyalinosis and sclerosis with increased mesangial matrix substance, compatible with features of diabetic nephropathy, in which the obliteration of glomerular capillary lumina and adhesions to Bowman's capsule were frequently observed in control OLETF rats, but typical mesangial nodular lesions were rarely encountered. The results of morphological analysis are presented in figure 4. Castration or estrogen administration significantly attenuated mesangial expansion close to level of LETO rats. Fractional mesangial volume (fig. 4A) was significantly bigger in control OLETF rats than in Cast, Est and LETO rats $(14.4 \pm 1.8 \%$ in control OLETF rats vs. $9.8 \pm$ $0.5 \%$ in Cast rats, $10.7 \pm 1.3 \%$ in Est rats and $8.9 \pm 1.4 \%$ in LETO rats, $p<0.001$ for each). There were no significant differences in this respect among Cast, Est and LETO rats. The results of GV appear in figure 4B. Castra- tion significantly reduced the mean $\mathrm{GV}$ to levels close to those of LETO rats $\left(1.86 \pm 0.26 \mu \mathrm{m}^{3} \times 10^{6}\right.$ in control OLETF rats, $1.34 \pm 0.18 \mu \mathrm{m}^{3} \times 10^{6}$ in Cast rats and 1.23 $\pm 0.08 \mu \mathrm{m}^{3} \times 10^{6}$ in LETO rats), while estrogen administration did not reduce the GV $\left(1.88 \pm 0.24 \mu \mathrm{m}^{3} \times 10^{6}\right.$ in Est rats), which was equal to those of control OLETF rats.

The electron microscopic examination revealed no electron-dense deposits in any of four groups even at 60 weeks of age. As shown in figure 4C, castration and estrogen administration significantly reduce the thickness of the GBM $(548 \pm 52 \mathrm{~nm}$ in control OLETF rats vs. $470 \pm$ $38 \mathrm{~nm}$ in Cast rats or $482 \pm 34 \mathrm{~nm}$ in Est rats) to levels close to those of LETO rats ( $461 \pm 14 \mathrm{~nm}$ in LETO rats).

The incidences of glomerulosclerotic lesions were 16.7 $\pm 5.2 \%$ (control OLETF rats), $3.3 \pm 2.8 \%$ (Cast rats), $27.1 \pm 17.8 \%$ (Est rats) and $0 \pm 0 \%$ (LETO rats), respectively. In control OLETF rats, mild tubulointerstitial changes (mean score $1.2 \pm 0.4$ ) were noted in association with glomerular sclerotic changes. Castration significantly attenuated glomerular injury (sclerosis index, SI, $5.7 \pm$ $3.9, \mathrm{p}<0.001$ ) and tubulointerstitial changes (mean score $0.4 \pm 0.5, p<0.01)$. In contrast, estrogen treatment failed to attenuate both glomerular injury (SI, $39.8 \pm 22.1)$ and tubulointerstitial changes (mean score $1.5 \pm 0.8$ ) which were almost equal to those of control OLETF rats (fig. 4D). There were no significant differences in SI and tubulointerstitial changes between control OLETF rats and Est rats. In LETO rats as a normal control, neither glomerulosclerotic nor tubulointerstitial lesions were observed. 


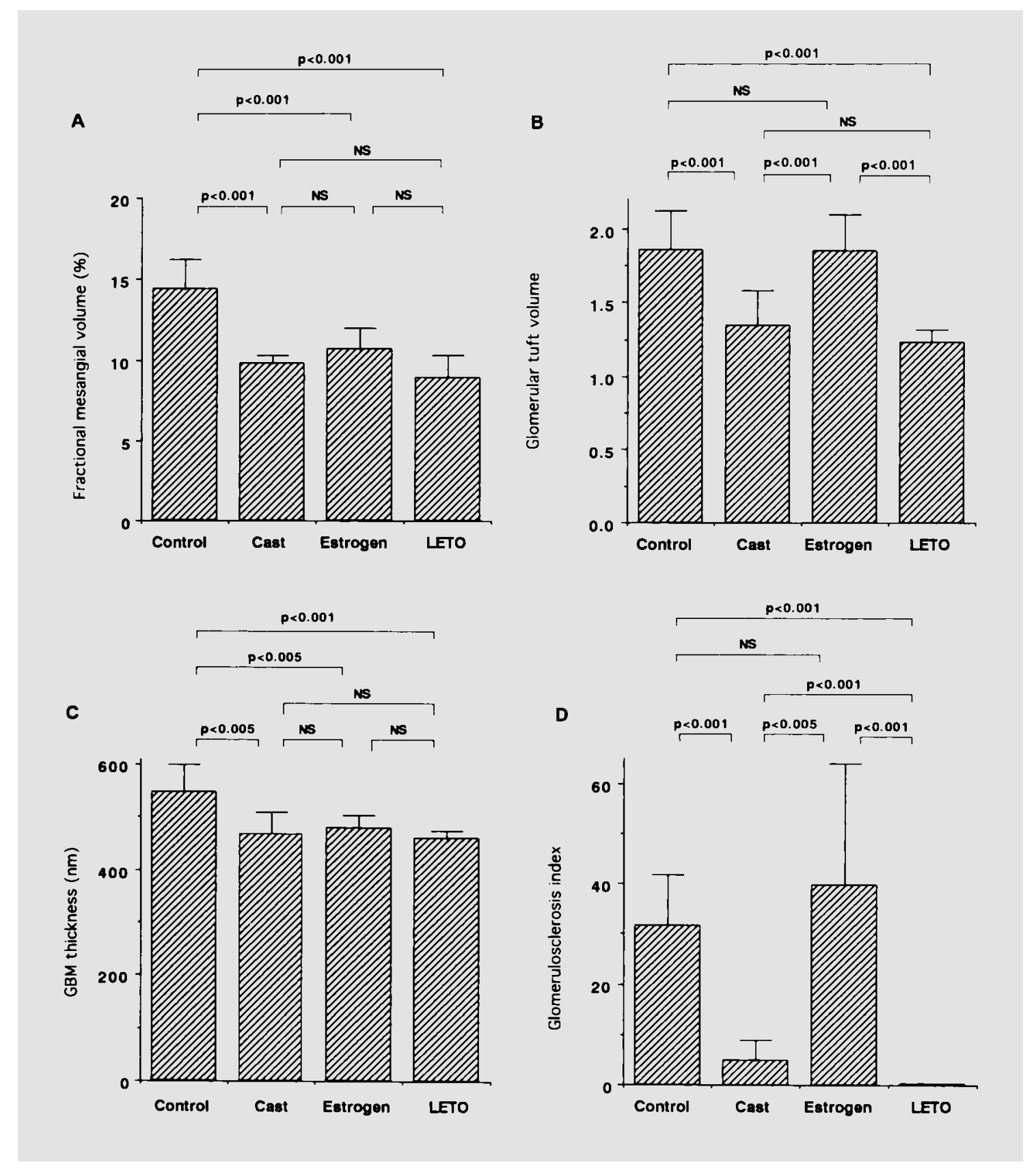

Fig. 4. Morphological data at 60 weeks of age.

We investigated the association of SI with GV, serum $\mathrm{GH}$ and Tchol levels in all three OLETF groups. There was no significant correlation between SI and GH levels $(r=0.103, p=0.667)$, while a statistically significant correlation was found between SI and the GV $(r=0.532, p<$ $0.01)$ or Tchol $(\mathrm{r}=0.611, \mathrm{p}<0.005)$.

Effect of Castration and Estrogen in OLETF Rats

\section{Discussion}

Testosterone has been shown to reduce glucose tolerance [20] and probably thereby to promote the development of DM $[5,6]$, whereas estrogen reportedly suppressed or delayed the development of DM [21]. In fact, in OLETF rats orchiectomy significantly reduces the de-

Nephron 2002;92:860-867 865 
velopment of DM in males, whereas ovariectomy enhances its development in females [5, 6]. In this experiment, castration or estrogen treatment significantly improved glucose tolerance and reduced serum testosterone levels, which suggested that each treatment might suppress or delay the development of DM.

Mesangial expansion and thickening of the GBM are the hallmarks representing histologically the initial stage of diabetic nephropathy [22]. The occurrence of diffuse mesangial lesions seems to be major contributing factor to the development of glomerular sclerosis found in the late stage of diabetic nephropathy [23]. The OLETF rat has been reported to exhibit these typical findings of diabetic nephropathy such as mesangial lesions and focal/segmental sclerosis and thickening of the GBM [7]. In this study, castration or estrogen treatment equally improved glucose tolerance, but exhibited a different effect on glomerular injury. Castration attenuated proteinuria, glomerular sclerosis, mesangial expansion, and GBM thickening. On the other hand, estrogen treatment did not attenuate proteinuria or glomerular sclerosis despite having ability to attenuate mesangial expansion and GBM thickening. These findings suggest that besides the mechanisms involved in the development of diabetic nephropathy, other mechanisms may contribute to progression of glomerulosclerosis in the estrogen-treated OLETF rats.

In contrast to the present study, castration in rats with streptozotocin diabetes decreased blood pressure, and attenuated GBM thickening, but failed to affect albuminuria and mesangial expansion [24]. Although the reason for unexpected dissociation between markers of injury is unknown, the dissociation may depend on gender or species of experimental animals.

In this study, a significant correlation between the GV and SI was found. Because a close correlation between glomerular hypertrophy and the incidence of glomerulosclerosis has been reported [25], this finding suggests that the failure of attenuating effect of estrogen treatment on glomerular injury may be related to non-attenuating effect on glomerular hypertrophy. Because an association between $\mathrm{GH}$ and glomerulosclerosis has been proposed and shown by the experiments using transgenic mice expressing these hormones [26-28], this different effect of castration and estrogen on glomerular injury may be related to a significant difference in serum GH levels between the castrated OLETF rats and the estrogen-treated OLETF rats. A significant increase in $\mathrm{GH}$ levels was observed in the estrogen-treated OLETF rats. These results suggest that glomerular hypertrophy is probably related to increased GH levels in the estrogen-treated OLETF rats, similar to what has been observed previously in uninephrectomized Sprague-Dawley rats [29]. In addition, we have recently reported that the somatostatin analogue attenuates estrogen-induced augmentation of glomerular injury in spontaneous hypercholesterolemic female Imai rats associated with a reduction of glomerular hypertrophy [30]. On the basis of these results and findings, it is possible that glomerular hypertrophy may be responsible for renal damage [25].

Negative effect of estrogen have been reported in the Cohen diabetic rat, another genetic model diabetes [31, 32]. The finding is very similar to what has been found in the present study. Although the exact mechanism is unknown, estrogen seems to exert a dual effect on glomerular injury in this experiment; firstly attenuating effect on diabetic nephropathy by suppressing plasma glucose, evidenced by a reduction of the GBM width and an attenuation of mesangial lesions and secondly a conversely augmenting effect by enhancing glomerular hypertrophy. As a whole, the effect of estrogen may depend on the balance of its attenuating and conversely augmenting effects. In this experiment, enhanced glomerular hypertrophy would cancel the estrogen's attenuating effect on glomerular injury.

The estrogen-treated OLETF rats showed higher levels of serum total cholesterol and triglycerides than did the control OLETF rats, and higher blood pressure than the castrated OLETF rats. Because these three parameters are important factors in influencing the progression of glomerular injury [33-35], and estrogen is reported to accelerate the development of renal disease in female obese Zucker rats [35] and in female analbuminemic rats [36] in association with an increase in triglycerides and cholesterol, the contribution of these factors to glomerular injury observed in the estrogen-treated OLETF rats should be considered.

In conclusion, although castration and estrogen treatment equally improved glucose tolerance, each had a different effect on glomerular injury; attenuating effect of castration but not of estrogen. Besides the mechanisms involved in the development of diabetic nephropathy, other mechanisms concerning $\mathrm{GH}$, blood pressure, serum cholesterol and triglycerides may be at least involved and contribute to the development of glomerulosclerosis, leading to a difference in glomerular injury between the castrated and the estrogen-treated OLETF rats. 


\section{References}

1 Kawano K, Hirashima T, Mori S, Saitoh Y, Kurosumi M, Natori T: Spontaneous long-term hyperglycemic rat with diabetic complications: Otsuka Long-Evans Tokushima Fatty (OLETF) Strain. Diabetes 1992;41:14221428.

2 Clark JB, Palmer CJ, Shaw WN: The diabetic Zucker fatty rat. Proc Soc Exp Biol Med 1983; 173:68-75.

3 Boucher DW, Hayashi K, Rosenthal J, Notkins AL: Virus-induced diabetes mellitus. III. Influence of the sex and strain of the host. J Infect Dis 1975;131:462-466.

4 Ikeda $\mathrm{H}$, Shino A, Matsuo T, Iwatsuka $\mathrm{H}$, Suzuoki Z: A new genetically obese-hyperglycemic rat (Wistar fatty). Diabetes 1981;30: 1045-1050.

5 Shi K, Mizuno A, Sano T, Ishida K, Shima K: Sexual difference in the incidence of diabetes mellitus in Otsuka-Long-Evans-TokushimaFatty rats: Effects of castration and sex hormone replacement on its incidence. Metabolism 1994;43:1214-1220.

6 Hirashima T, Kawano K, Mori S, Natori T: The influence of testosterone on the spontaneous hyperglycaemic Otsuka Long-Evans Tokushima Fatty (OLETF) rat. Int Diabetes 1996; 4:85-92.

7 Fukuzawa Y, Watanabe Y, Inaguma D, Hotta $\mathrm{N}$ : Evaluation of glomerular lesion and abnormal urinary findings in OLETF rats resulting from a long-term diabetic state. J Lab Clin Med 1996;128:568-578.

8 Ohtsuka N, Sakemi T, Shouno Y, Morito F: Attenuating effect of castration or estrogen administration on glomerular injury in adriamycin-induced nephropathy of rats. Nephrology 1996;2:45-52.

9 Fujita Y: Color reaction between pyrogallol red-molybdenum (VI) complex and protein. Bunsekikagaku 1983;32:E379-386.

10 Gornall AG, Bardawill CJ, David MM: Determination of serum proteins by means of the biuret reaction. J Biol Chem 1949;177:751761.

11 Taussky HH: A microcolorimetric determination of creatinine in urine by Jaffe's reaction. J Biol Chem 1954;208:853-861.

12 Allain CC, Poon LS, Chan CS: Enzymatic determination of total serum cholesterol. Clin Chem 1974;20:470-475.
13 Banauch D, Brummer W, Ebeling W, Metz H, Rindfrey H, Lang H, Leybold K, Rick W, Staudinger HJ: A glucose dehydrogenase for the determination of glucose concentrations in body fluids. J Clin Chem Clin Biochem 1975; 13:101-107.

14 Keizer H, Janssen GME, Menheere P, Kranenburg G: Changes in basal plasma testosterone, cortical, and dehydroepiandrosterone sulfate in previously untrained males and females preparing for a marathon. Int J Sports Med 1989; 10:S139-S145.

15 Raij L, Azar S, Keane W: Mesangial immune injury, hypertension, and progressive glomerular damage in Dahl rats. Kidney Int 1984;26: 137-143.

16 Sakemi T, Baba N: Castration attenuates proteinuria and glomerular injury in hyperlipidemic Imai rats. Nephron 1993;64:429-435.

17 Suzuki D, Miyazaki M, Jinde K, Koji T, Yagame M, Endoh M, Nomoto Y, Sakai H: In situ hybridization studies of matrix metalloproteinase-3, tissue inhibitor of metalloproteinase-1 and type IV colloagen in diabetic nephropathy. Kidney Int 1997;52:111-119.

18 Weibel ER: Practical Methods for Biological Morphometry. Stereological Methods. London, Academic Press, 1979, vol 1, pp 1-145.

19 Jensen EB, Gundersen HJG, Osterby R: Determination of membrane thickness distribution from orthogonal intercepts. J Microsc 1979; 115:19-23.

20 Shoupe D, Lobo RA: The influence of androgens on insulin resistance. Fertil Steril 1984;41: 385-388.

21 Lewis JT, Foglia VG, Rodrigues RR: The effects of steroids on the incidence of diabetes in rats after subtotal pancreatectomy. Endocrinology 1950;46:111-121.

22 Adler S: Structure-function relationships associated with extracellular matrix alterations in diabetic glomerulopathy. J Am Soc Nephrol 1994;5:1165-1172.

23 Mauer SM, Steffes MW, Ellis EN, Sutherland DE, Brown DM, Goetz FC: Structural-functional relationships in diabetic nephropathy. $\mathrm{J}$ Clin Invest 1984;74:1143-1155.

24 Bach LA, Cooper ME, Vranes D, Allen TJ, Rumble J, Jerums G: Disparate effects of castration on renal structure and function in the streptozotocin diabetic rat. Diabetes Res 1994; 27:27-38.

25 Yoshida Y, Kawamura T, Ikoma M, Fogo A, Ichikawa I: Effects of antihypertensive drugs on glomerular morphology. Kidney Int 1989; $36: 626-635$.
26 EL Nahas M, Bassetta AH, Cope GH, Carpentier JE: Role of growth hormone in the development of experimental renal scarring. Kidney Int 1991;40:29-34.

27 Doi T, Striker LJ, Quaife C, Conti FG, Palmiter R, Behringer R, Brinster R, Striker GE: Progressive glomerulosclerosis develops in transgenic mice chronically expressing growth hormone and growth hormone releasing factor but not in those expressing insulin-like growth factor-1. Am J Pathol 1988;131:398-403.

28 Doi T, Striker LJ, Gibson CC, Agodoa LYC, Brinster RL, Striker GE: Glomerular lesions in mice transgenic for growth hormone and insulin-like growth factor-1. 1. Relationship between increased glomerular size and mesangial sclerosis. Am J Pathol 1990;137:541-552.

29 Ohtsuka N, Sakemi T, Tomiyoshi Y, Morito F: Different effect of estrogen administration from castration on glomerular injury in unilaterally nephrectomized male Sprague-Dawley rats. Nephron 1997;77:445-451.

30 Nakamura M, Ikeda Y, Mine M, Tomiyoshi Y, Sakemi T: Somatostatin analogue attenuates estrogen-induced augmentation of glomerular injury in spontaneous hypercholesterolemic female Imai rats. Nephron 2001;89:448-454.

31 Cohen AM, Rosenmann E: Effect of the estrogen antagonist, tamoxifen, on development of glomerulosclerosis in the Cohen diabetic rat. Diabetes 1985;34:634-638.

32 Rosenmann E, Yanko L, Cohen AM: Female sex hormone and nephropathy in Cohen diabetic rat (genetically selected sucrose-fed). Horm Metab Res 1984;16:11-16.

33 Kasiske BL, O’Donnell MP, Cleary MP, Keane WF: Treatment of hyperlipidemia reduces glomerular injury in obese Zucker rats. Kidney int 1988;33:667-672.

34 Greco F, Davis WA, Simon NM, Huang C, Huang C, Krumlovsky FA: Hypertension of chronic renal failure: Role of sodium and the renal pressor system. Kidney Int 1975;7:S176S183.

35 Gades MD, Stern JS, van Goor H, Nguyen D, Johnson PR, Kaysen GA: Estrogen accelerates the development of renal disease in female obese Zucker rats. Kidney Int 1998;53:130_ 135.

36 Joles JA, van Goor Harry, Koomans HA: Estrogen induces glomerulosclerosis in analbuminemic rats. Kidney Int 1998;53:862-868. 